\title{
Effect of different drying treatments on the physicochemical, functional, and antioxidant properties of Bacopa monnieri
}

\author{
Bhuban Mohan Padhiari ${ }^{1}$, Asit Ray ${ }^{1}$, Sudipta Jena ${ }^{1}$, Bibhuti Bhusan Champati ${ }^{1}$, Ambika Sahoo ${ }^{1}$, \\ Tarun Halder ${ }^{2}$, Biswajit Ghosh ${ }^{2}$, Pratap Chandra Panda ${ }^{1}$, Sanghamitra NayaK ${ }^{1 *}$ \\ ${ }^{1}$ Centre for Biotechnology, Siksha 'O' Anusandhan University, Bhubaneswar, Odisha, India \\ ${ }^{2}$ P. G. Department of Botany, Ramakrishna Mission Vivekananda Centenary College, Rahara, Kolkata, West Bengal, India
}

\begin{abstract}
Bacopa monnieri (L.) Wettst is a very high-value medicinal plant that is commonly used for improving cognitive functions. However, the availability of very limited information on the drying method of $B$. monnieri has prompted to optimize a suitable drying method. The present study therefore aimed to evaluate the influence of the following six drying treatments on the quality of $B$. monnieri sample: microwave drying at $300 \mathrm{~W}$ and $600 \mathrm{~W}$, hot air-drying at $50^{\circ} \mathrm{C}$ and $70^{\circ} \mathrm{C}$, solar drying, and freeze-drying (FD). The quality attributes of the dried samples were comparatively analyzed in terms of color, total color difference, moisture content, water activity $\left(a_{\mathrm{w}}\right)$, antioxidant activity, and bacoside A and bacopaside I content. The results of this study showed significant differences $(P<0.05)$ among the different drying methods in International Commission on Illumination (CIE) parameters, namely lightness index $\left(L^{*}\right)$, red-green index $\left(a^{*}\right)$, and yellow-blue index $\left(b^{*}\right), \Delta E$ and $a_{\mathrm{w}}$ values. Among the samples dried with the six drying methods, freeze-dried $B$. monnieri samples had an attractive color with the lowest total color difference value (11.415\%), $a_{\mathrm{w}}$ value $(0.15 \%)$, and maximum bacoside A (3.389\%) and bacopaside I $(0.620 \%)$ content. Moreover, Fourier transform infrared spectroscopy (FT-IR) analysis showed no major difference in the functional groups in B. monnieri samples processed by the different drying methods. Considering the retention of quality after drying, FD was found to be very effective for future large-scale production of good quality dried B. monnieri products.
\end{abstract}

Key words: Bacopa monnieri (L.) Wettst, bacoside A, bacopaside I, drying treatments, DPPH assay, HPLC, FT-IR

\section{Introduction}

Bacopa monnieri (L.) Wettst (Family: Scrophulariaceae), locally known as Brahmi in India, is a perennial, creeping, glabrous, succulent herb with rooting at nodes, and it is distributed in the warmer and marshy wetland regions of India, East Asia, Australia, and the United States (Bhandari et al., 2020). It is a very high-value medicinal plant used in Indian and Chinese traditional medicine as a nerve tonic, memory enhancer, diuretic, and carminative and for the treatment of asthma, epilepsy, and dementia (Christopher et al., 2017). Furthermore, the nootropic herb $B$. monnieri helps in restoring synaptic activity, neuron synthesis, and repairing of damaged neurons (Jeyasri et al., 2020). B. monnieri contains different classes of compounds such as alkaloids (brah- mine, nicotine, and herpestine), steroids (stigmasterol, stigmastanol, and $\beta$-sitosterol), flavonoids (apigenin and luteolin), and saponins (hersaponin, monnierin, bacopaside I, bacoside A, and bacoside B) (Saha et al., 2020). Studies have shown that the major bioactive compound of $B$. monnieri, i.e., bacoside, contributes to the broadspectrum pharmacological activity such as memory enhancing, antidepressant, antidiabetic, anticancer, antimicrobial, anti-inflammatory, neuroprotective, and hepatoprotective activities (Williamset al., 2014; Christopher et al., 2017;Bhatia et al., 2017; Palethorpe et al., 2018; Saini et al., 2019; Bhandari et al., 2020). The retention of bacoside in $B$. monnieri during the post-harvest process (drying and storage) is a concern for the industry. Generally, B. monnieri is dried using traditional

\footnotetext{
* Corresponding author: Centre for Biotechnology, Siksha 'O' Anusandhan University, Bhubaneswar, Odisha, India; e-mail: sanghamitran24@gmail.com
} 
drying methods such as sun drying, drying in shade, and polyhouse drying; however, these methods have several disadvantages such as environmental dependency and longer duration, which lead to inconsistent quality and contamination problems (Silpa et al., 2021). Hence, these methods are unsuitable for food and pharmaceutical industries.

The World Health Organization (WHO) reported that $80 \%$ of the world's population use herbal medicine mainly for primary health care (Verma, 2014). Although medicinal herbs are rich sources of bioactive compounds, the quality of medicinal herbs varies with the species, origin, agricultural system, climate, maturity, and postharvest treatments ( $\mathrm{Li}$ et al., 2019). Drying technology is one of the most significant, simplest, and oldest food preservation techniques among different postharvest treatments. Drying causes the release of volatile substances (moisture) to yield a solid product through the removal of moisture or, more precisely, through reduction in water activity $\left(a_{\mathrm{w}}\right)$. Over the past few years, several advanced drying methods such as microwave drying (MD), microwave-assisted hot-air drying, solar drying (SD), and freeze-drying (FD) have been developed with significant advantages in terms of convenience, cost, consumption time, high-quality end product, and environmental impact (Yuan et al., 2020). The moisture-mediated deteriorative reactions and the growth of microorganisms can be prevented by the removal of moisture from foods. Unfavorable drying condition (higher temperature and long exposure time) causes physicochemical changes such as crust formation, sensory quality reduction, enzyme inactivation, nutrient loss, and change in shape, color, and texture of foods and botanicals (Vega-Gálvez et al., 2012). The physicochemical properties of raw food and medicinal herb can be maintained to a greater extent by drying the sample under controlled conditions (Nagaya et al., 2006). Heat-sensitive foods and agricultural products (spices and herbs) are preferably processed at low temperatures. Limited information is available on the effect of different drying methods on bacoside A content in B. monnieri. Drying methods also have an important impact on antioxidant activities. However, from the previous literature report, we found that none of the authors have optimized advanced drying methods and studied their influence on physicochemical characteristics of bacoside A and bacopaside I content in $B$. monnieri.
Therefore, in the present study, an investigation was conducted to evaluate the influence of the following six drying methods on the appearance and content of bioactive compounds (bacoside A and bacopaside I) in $B$. monnierr. $\mathrm{MD}(300 \mathrm{~W}$ and $600 \mathrm{~W})$, hot-air oven drying (HAD) $\left(50\right.$ and $\left.70^{\circ} \mathrm{C}\right), \mathrm{SD}$, and FD. The quality, physicochemical characteristics, and antioxidant activity of samples obtained by the different drying methods were tested using the color index, rehydration ratio, $a_{\mathrm{w}}$, in vitro $\mathrm{DPPH}$ assay, high-performance liquid chromatography (HPLC) for analyzing bacoside A and bacopaside I content, and Fourier transform infrared spectroscopy (FT-IR) analysis. The data obtained can be used to choose a suitable drying method that enhances the product quality retention and promotes the industrial production of B. monnieri.

\section{Materials and methods}

\section{Raw plant materials and sample preparation}

Fresh $B$. monnieri sample was collected from Brahmagiri (located at $19^{\circ} 47^{\prime} 35.45^{\prime \prime} \mathrm{N}, 85^{\circ} 38^{\prime} 28.77^{\prime \prime} \mathrm{E}$ and $12 \mathrm{~m}$ above the sea level), Odisha, India in September 2020. The plant samples were identified and authenticated by Principal Scientist, Taxonomy and Conservation Division, Regional Plant Resource Centre, and voucher specimens (RPRC/12528) were deposited in the herbarium of the institute. The samples were properly washed and drained off to remove the excess water. The samples were then chopped with a scissor into segments of equal length $(2 \mathrm{~cm})$.

\section{Chemicals and reagents}

Water, methanol, and acetonitrile of HPLC grade were procured from Sigma Aldrich Co. (St. Louis, MO, USA). Orthophosphoric acid; 2, 2-diphenyl-1-(2, 4, 6-trinitrophenyl) hydrazyl (DPPH); and potassium dihydrogen phosphate were procured from Merck India Ltd., Mumbai, India. Reference standards such as bacopaside I and bacoside A of purity $>95 \%$ were purchased from Natural Remedies Private Limited (Bangalore, India). Stock solutions were prepared by dissolving the accurate weight of the two standards in methanol and stored at $4^{\circ} \mathrm{C}$ for further analysis.

\section{Drying experiments}

The chopped B. monnieri samples were subjected to the following six drying methods until constant moisture 
content was achieved: $\mathrm{MD}$ at $300 \mathrm{~W}$ and $600 \mathrm{~W}, \mathrm{HAD}$ at $50^{\circ} \mathrm{C}$ and $70^{\circ} \mathrm{C}$, SD, and FD. All the drying experiments were performed in triplicate. All the specific drying procedures are described below.

\section{MD method}

The MD method was performed in a microwave oven (Samsung, model: CE76JD-B/XTL) at $300 \mathrm{~W}$ and $600 \mathrm{~W}$ by taking $100 \mathrm{~g}$ of freshly chopped $B$. monnieri samples. The process of drying was continued until the difference in weight loss between the successive measurements was $<0.1$ g. During the drying process, the amount of moisture loss from the materials was recorded intermittently (every $2 \mathrm{~min}$ ) by weighing the sample prior to drying and after drying using a digital weight balance machine (ELB 300, Shimadzu). The dried samples were then immediately packed into a zipper poly bag and stored in a desiccator for further analysis.

\section{HAD method}

The effect of $\mathrm{HAD}$ at $50^{\circ} \mathrm{C}$ and $70^{\circ} \mathrm{C}$ was tested by taking $100 \mathrm{~g}$ of chopped fresh $B$. monnieri samples. The drying process started from $87 \%$ of moisture content $\left(\mathrm{M}_{0}\right)$ until the weight loss difference was $<0.1 \mathrm{~g}$ between successive estimations. Moisture loss of the sample was measured intermittently every $1 \mathrm{~h}$ by weighing the same sample using a digital balance with $0.1 \mathrm{~g}$ precision. The total amount of moisture content and moisture loss was estimated by recording weight of the sample after drying and before drying. The dried samples were immediately packed in a zipper poly bag and stored in a desiccator for further analysis.

\section{FD method}

The FD method was performed by placing $100 \mathrm{~g}$ of chopped $B$. monnieri samplesin a freeze dryer or lyophilizer (SCANVAC Coolsafe, Denmark) at $-40^{\circ} \mathrm{C}$ for $24 \mathrm{~h}$. The moisture loss of the materials was measured by weighing the sample every $1 \mathrm{~h}$ until a constant weight was achieved. The samples were frozen in a $-20^{\circ} \mathrm{C}$ refrigerator for $24 \mathrm{~h}$ prior to the FD process. The dried samples were immediately packed in a zipper poly bag for further analysis.

\section{$S D$ method}

The SD method was performed by placing $100 \mathrm{~g}$ of chopped $B$. monnieri samples in a tray, and the tray was kept inside the cabinet of a solar dryer assembled with a solar panel to run the fan coupled with a photovoltaic module of $50 \mathrm{~W}$. The moisture loss of the materials was measured by weighing the sample every $1 \mathrm{~h}$ until a constant weight was obtained.

\section{Analysis of drying experiments}

\section{Moisture content}

Moisture content (\%) of the dried B. monnieri sample was recorded in triplicate by intermittently weighing the respective sample using the digital weight balance machine until a constant weight was achieved with $0.01 \mathrm{~g}$ accuracy. The moisture content of each dried sample was then determined using the following formula:

Moisture content $[\%]=\frac{\text { Initialweight }- \text { Finalweight }}{\text { Initialweight }} \times 100$

\section{Color measurement}

The dried B. monnierisamples obtained from the six drying methods were powdered, poured into Petridishes, and covered with a transparent film. By using the International Commission on Illumination (CIE) parameters, namely lightness index $\left(L^{*}\right)$, red-green index $\left(a^{*}\right)$, and yellow-blue index $\left(b^{*}\right)$, the color value was measured with a colorimeter (Model-SL CR60, China). Prior to the measurement of the color value, the colorimeter was calibrated using a standard white surface $(L=96.12$, $a=-0.13, b=-0.30)$. The values of three color coordinates, namely $L^{*}, a^{*}$, and $b^{*}$, were taken to measure the whiteness value of a sample ranging from black at 0 to white at 100 , red $\left(+a^{*}\right)$ and green $\left(-a^{*}\right)$, and yellow $\left(+b^{*}\right)$ and blue $\left(-b^{*}\right)$. The analysis was performed in triplicate, and the average values were calculated. The total color difference $(\Delta E)$ of the dried $B$. monnieri sample with reference to a fresh sample was calculated using the following equation:

$$
\Delta E=\sqrt{\left(L_{0}^{*}-L^{*}\right)^{2}+\left(a_{0}^{*}-a^{*}\right)^{2}+\left(b_{0}^{*}-b^{*}\right)^{2}}
$$

where $L_{0}^{*}, a_{0}^{*}$, and $b_{0}^{*}$ are the color values of the fresh sample considered as control and $L^{*}, a^{*}$, and $b^{*}$ are the measured color values of the dried sample.

\section{The $a_{w}$ and rehydration capacity}

The $a_{\mathrm{w}}$ values of the different dried $B$. monnieri samples $\left(a_{\mathrm{w}}\right)$ were measured at $25^{\circ} \mathrm{C}$ by using a water activity meter (WA-60A), and the values are expressed as percentage. Rehydration is the process of restoring the water content of a dehydrated product. Rehydration attri- 
bute is one of the quality parameters of dried products and is tested to determine whether any physicochemical changes occurred in sample composition during the drying process and pretreatment. The rehydration experiment was performed by adding $2 \mathrm{~g}$ of dried samples into a beaker containing $50 \mathrm{ml}$ of water, and the beaker was left undisturbed for $16 \mathrm{~h}$. The samples were then taken out into dishes, and excess water was soaked by an absorbent paper. The sample weight was recorded, and the rehydration ratio was calculated using Equation 3:

$$
\text { Rehydration ratio }=W_{\mathrm{r}} / W_{\mathrm{d}}
$$

where $W_{\mathrm{d}}$ and $W_{\mathrm{r}}$ represent the weight of the dehydrated and rehydrated samples, respectively.

The rehydration capacity calculated as the percentage of water regain was determined from the sample weight difference between pre and post rehydration using the following equation:

$$
R C=\frac{M r}{M o-M e} \times 100 \%
$$

where $M r, M o$, and $M e$ are weights of the rehydrated sample, post-rehydrated sample, and pre-rehydrated sample, respectively.

\section{DPPH radical scavenging assay}

The DPPH radical scavenging assay was performed according to the protocol of Ray et al. (2019) by mixing different concentrations $(0.1,0.5,2,5,10$, and $25 \mathrm{mg} / \mathrm{ml})$ of the dried samples of $B$. monnieri aerial parts with $1 \mathrm{ml}$ of 2,2-diphenyl-1-picrylhydrazyl solution $(1 \mathrm{mg} / 25 \mathrm{ml}$ of methanol). The mixture was shaken firmly to achieve uniform mixing and allowed to undergo oxidation reaction for $30 \mathrm{~min}$ at room temperature. The absorbance was then recorded at $517 \mathrm{~nm}$ wave length in a UV-Vis spectrophotometer (Model: Evolution 220, Thermo Scientific, China). In the present study, the radical scavenging ability was calculated on the basis of half-maximal inhibitory concentration $\left(\mathrm{IC}_{50}\right)$ value, which is the concentration of the sample at which the scavenging rate reaches 50\% (Kozarski et al., 2011). Thus, a sample with a stronger scavenging ability will show a lower $\mathrm{IC}_{50}$ value. Antioxidant activity was calculated using the following equation:

DPPH radical scavenging $[\%]=$

$$
=\left[\left(A_{\text {control }}-A_{\text {sample }}\right) / A_{\text {control }}\right] \times 100
$$

In Equation 5, the absorbance of the fresh sample and the dehydrated sample is denoted by $A_{\text {control }}$ and $A_{\text {sample }}$, respectively.

\section{HPLC analysis}

To quantify bioactive compounds (bacopaside I and bacoside A), HPLC analysis of fresh and dried B. monnieri samples was performed using a modular HPLC instrument (Shimadzu, Kyoto, Japan) assembled with a binary LC-20 AD pump, a SPD-20 A diode array detector, a Rheodyne 8125 injector, and a CTO-20AC column oven. The separation was achieved using a $\mathrm{C} 18$ reverse-phase column (Restek Pinnacle DB, USA, $250 \times$ $\times 4.6 \mathrm{~mm}, 5 \mu \mathrm{m}$ ) with the binary gradient mode involving orthophosphate buffer ( $\mathrm{pH}$ 2.4) in HPLC grade water as solvent $\mathrm{A}$ and acetonitrile as solvent $\mathrm{B}$. The gradient program was set as follows: $0-0.01 \mathrm{~min}, 0-30 \% \mathrm{~B}$; 0.01-25 min, $30-40 \%$ B; $25-26$ min, $40-30 \%$ B; 26-30 min, 30-30\% B. Column temperature was set at $27^{\circ} \mathrm{C}$. The flow rate and injection volume of each sample and standard solution were set to $1.5 \mathrm{ml} / \mathrm{min}$ and $20 \mu \mathrm{l}$, respectively. The detector wavelength was set at $205 \mathrm{~nm}$ for acquiring the chromatograms. Prior to HPLC analysis, the freshly prepared mobile phase was filtered using a 0.45 - $\mu \mathrm{m}$-diameter membrane filter and degassed using a sonicator.

\section{FT-IR analysis}

The FT-IR analyses of six different dried powdered samples of $B$. monnieri aerial parts were performed in an FT-IR instrument (Model: 4600LE, Jasco, Japan) equipped with an ATR (attenuated total reflectance) diamond crystal according to the method of Feng et al. (2021). Spectral information was recorded in the transmission mode in the wave number range of $400-4000 \mathrm{~cm}^{-1}$ at the resolution of $4 \mathrm{~cm}^{-1}$.

\section{Statistical analysis}

All the six drying experiments were completed in triplicate, and the obtained values are expressed as mean value \pm standard deviation (SD). One-way analysis of variance (ANOVA) followed by Tukey's multiple comparison post-test was performed using Minitab 17 software (Minitab Inc., State College, PA, USA) to analyze significant differences $(P<0.05)$ among the different drying treatments. 


\section{Results and discussion}

\section{Effect of drying treatments on the moisture content of B. monnieri}

In this study, fresh $B$. monnieri aerial parts were dried using the following six drying methods: MD $300 \mathrm{~W}$, $\mathrm{MD} 600 \mathrm{~W}, \mathrm{HAD} 50^{\circ} \mathrm{C}, \mathrm{HAD} 70^{\circ} \mathrm{C}, \mathrm{SD}$, and $\mathrm{FD}$. The moisture content of all the dried $B$. monnieri samples was remarkably reduced after drying, from $87 \%$ to approximately $12.24 \%$. As shown in Table 1 , the FD method took the longest dehydration time $(24 \mathrm{~h})$, followed by $\mathrm{HAD}$ at $50^{\circ} \mathrm{C}(13 \mathrm{~h}), \mathrm{SD}(8 \mathrm{~h}), \mathrm{HAD}$ at $70^{\circ} \mathrm{C}(7.4 \mathrm{~h})$, $\mathrm{MD}$ at $300 \mathrm{~W}(0.5 \mathrm{~h})$, and MD at $600 \mathrm{~W}(0.23 \mathrm{~h})$ to dry the $B$. monnieri sample. The significant variation $(P<0.05)$ in the dehydration time among the six drying methods may be due to the variation in the mode of energy transmission (Wang et al., 2014; Yanet al., 2019). Similar findings were reported for Thymys daenensis (Rahimmalek et al., 2013). The result of the different drying method revealed that MD was the fastest drying method. In MD, the electromagnetic energy is directly transformed into molecular kinetic energy that causes heat to be generated from within the material, which fastens the water evaporability from the leaves (Atungulu et al., 2019). In addition, MD was found to be the fastest drying method for Phyllanthus amarus (Nguyen et al., 2015) and Murraya koenigii (Shivanna et al., 2014). However, despite being a faster drying method, $\mathrm{MD}$ is not the preferred drying method as non uniformity of the electromagnetic field creates hot spots, leading to a poor quality of dried products (Therdthai et al., 2009).

\section{Effect of drying on color characteristics of B. monnieri}

The appearance of the dried $B$. monnieri powdered samples obtained with the six drying methods is shown in Figure 1(A-F). The FD sample showed a light green color as compared to fresh materials. The sample of $\mathrm{HAD}$ at $70^{\circ} \mathrm{C}$ had a lighter appearance than the samples of $\mathrm{HAD}$ at $50^{\circ} \mathrm{C}, \mathrm{MD}$ at $300 \mathrm{~W}$ and $600 \mathrm{~W}, \mathrm{SD}$, and FD treatments. In contrast, the samples of $\mathrm{MD}$ at $300 \mathrm{~W}$ and $600 \mathrm{~W}, \mathrm{SD}$, and $\mathrm{HAD}$ at $50^{\circ} \mathrm{C}$ had a brownish-yellow color. The test results of the color parameters of the six dried B. monnieri samples are summarized in Table 1. In addition, " $\Delta E$ " values were determined to quantify the color change potential of the samples of the six drying methods. We found that $\mathrm{L}^{*}{ }_{0}, \mathrm{a}^{*}{ }_{0}$, and $\mathrm{b}^{*}{ }_{0}$ index values
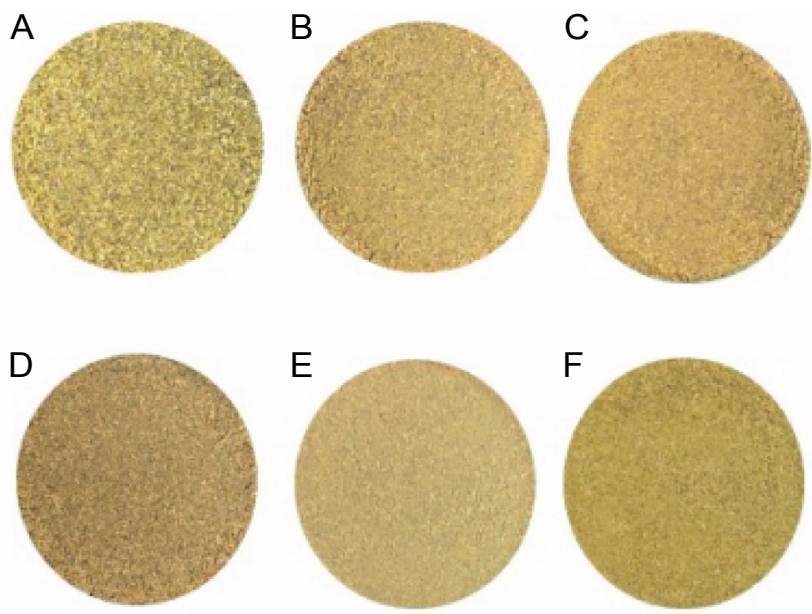

Fig. 1. Impact of the six different drying methods, namely microwave drying at $300 \mathrm{~W}(\mathrm{~A})$, microwave drying at $600 \mathrm{~W}(\mathrm{~B})$, hot air drying at $50^{\circ} \mathrm{C}(\mathrm{C})$, hot air drying at $70^{\circ} \mathrm{C}(\mathrm{D})$, solar drying $(\mathrm{E})$, and freeze drying $(\mathrm{F})$ on the appearance of fresh B. monnieri samples

were $39.73,-1.18$, and 13.47 , respectively, in the fresh sample. Among the six drying methods, the lowest $\mathrm{L}^{*}$ and $\Delta \mathrm{E}$ values were found in the FD sample, which is indicative of an ideal color (Hu et al., 2017), whereas the highest $\mathrm{L}^{*}$ and $\Delta \mathrm{E}$ values of $60.2 \pm 0.65^{\mathrm{a}}$ and $21.88 \pm 0.81^{\mathrm{a}}$, respectively, were found in the HAD at $70^{\circ} \mathrm{C}$ sample. In general, the color of the dried product is one of the most important quality parameters, as it plays a major role in consumer acceptance and market valuation (Wang et al., 2014). The result presented in Table 1 show that the color index of the different dried products was significantly influenced $(P<0.05)$ by the different drying treatments. The lightness, redness, and yellowness that increased after drying (Fig. 1) may be due to chlorophyll degradation or due to the occurrence of enzymatic and non-enzymatic browning reactions. When the samples were subjected to heat during MD, $\mathrm{SD}$, and $\mathrm{HAD}$ treatments, the heat generated caused the products to become brown and destroyed the natural color of the products (Izli et al., 2014). Rahimmalek and Goli (2013) reported that the reduction of green color might be due to the degradation of chlorophyll in the leaf of $T$. daenensis upon exposure to a higher temperature. Moreover, due to the high temperature, magnesium ion may be replaced by hydrogen in the chlorophyll molecule; consequently, chlorophyll is converted into pheophytin, there by leading to the loss of green color (Rudra et al., 2008). Generally, the FD method produced the 
Table 1. Color characteristics, moisture content, water activity, rehydration ratio, and time duration of $B$. monnieri samples processed by six different drying methods

\begin{tabular}{l|c|c|c|c|c|c|c|c}
\hline \multirow{2}{*}{$\begin{array}{c}\text { Drying } \\
\text { methods }\end{array}$} & \multicolumn{3}{|c|}{ Color attributes } & \multirow{2}{*}{$\begin{array}{c}\text { Moisture } \\
{[\%]}\end{array}$} & $\begin{array}{c}\text { Water } \\
\text { activity }\end{array}$ & $\begin{array}{c}\text { Rehydration } \\
\text { ratio [\%] }\end{array}$ & $\begin{array}{c}\text { Td } \\
{[\mathrm{h}]}\end{array}$ \\
\cline { 2 - 8 } & $\mathrm{L}^{*}$ & $\mathrm{a}^{*}$ & $\mathrm{~b}^{*}$ & - & - & - \\
\hline Fresh & $39.73 \pm 0.19^{\mathrm{d}}$ & $-1.78 \pm 0.15^{\mathrm{d}}$ & $13.47 \pm 0.10^{\mathrm{d}}$ & - & - & - \\
\hline $\mathrm{MD}[300 \mathrm{~W}]$ & $53.33 \pm 0.69^{\mathrm{bc}}$ & $-0.16 \pm 0.20^{\mathrm{c}}$ & $15.87 \pm 0.01^{\mathrm{b}}$ & $13.90 \pm 0.50^{\mathrm{cd}}$ & $14.7 \pm 0.01^{\mathrm{a}}$ & $0.38 \pm 0.01^{\mathrm{c}}$ & $4.52 \pm 0.51^{\mathrm{ab}}$ & 0.5 \\
\hline $\mathrm{MD}[600 \mathrm{~W}]$ & $55.18 \pm 1.87^{\mathrm{b}}$ & $1.78 \pm 0.04^{\mathrm{b}}$ & $13.86 \pm 0.08^{\mathrm{cd}}$ & $15.87 \pm 2.00^{\mathrm{c}}$ & $12.24 \pm 0.00^{\mathrm{e}}$ & $0.40 \pm 0.01^{\mathrm{b}}$ & $3.97 \pm 0.23^{\mathrm{bc}}$ & 0.23 \\
\hline $\mathrm{HAD}\left[50^{\circ} \mathrm{C}\right]$ & $58.13 \pm 0.74^{\mathrm{a}}$ & $1.84 \pm 0.08^{\mathrm{b}}$ & $14.18 \pm 0.03^{\mathrm{c}}$ & $18.76 \pm 0.61^{\mathrm{b}}$ & $12.6 \pm 0.06^{\mathrm{c}}$ & $0.43 \pm 0.01^{\mathrm{a}}$ & $3.85 \pm 0.29^{\mathrm{bc}}$ & 13 \\
\hline $\mathrm{HAD}\left[70^{\circ} \mathrm{C}\right]$ & $60.2 \pm 0.65^{\mathrm{a}}$ & $2.4 \pm 0.04^{\mathrm{a}}$ & $19.99 \pm 0.21^{\mathrm{d}}$ & $21.88 \pm 0.81^{\mathrm{a}}$ & $12.45 \pm 0.01^{\mathrm{d}}$ & $0.37 \pm 0.00^{\mathrm{c}}$ & $2.92 \pm 0.14^{\mathrm{d}}$ & 7.4 \\
\hline $\mathrm{SD}$ & $58.42 \pm 0.67^{\mathrm{a}}$ & $1.37 \pm 0.02^{\mathrm{b}}$ & $14.27 \pm 0.27^{\mathrm{c}}$ & $18.97 \pm 0.50^{\mathrm{b}}$ & $13.32 \pm 0.01^{\mathrm{b}}$ & $0.41 \pm 0.00^{\mathrm{b}}$ & $3.14 \pm 0.18^{\mathrm{cd}}$ & 8 \\
\hline $\mathrm{FD}$ & $51.06 \pm 0.04^{\mathrm{c}}$ & $-0.38 \pm 0.47^{\mathrm{c}}$ & $13.6 \pm 0.18^{\mathrm{d}}$ & $11.43 \pm 0.11^{\mathrm{d}}$ & $12.7 \pm 0.00^{\mathrm{c}}$ & $0.15 \pm 0.00^{\mathrm{d}}$ & $5.20 \pm 0.46^{\mathrm{a}}$ & 24 \\
\hline
\end{tabular}

Values are means $\pm \mathrm{SD}(n=3)$; for each column, values followed by different small superscript letter shared significant differences at $P<0.05$, based on Tukey test; MD - microwave drying, HAD - hot air drying, FD - freeze drying, SD - solar drying, Td - time duration, $\mathrm{L}^{*}-$ the lightness index, $\mathrm{a}^{*}$ - chromaticity index in the red-green axis; $\mathrm{b}^{*}$ - chromaticity index in the yellow-blue axis, $\Delta \mathrm{E}$ - total color difference is calculated by using the color of raw material as reference

best quality product in terms of color retention, which was close to that of the fresh $B$. monnieri sample. The obtained results are in accordance with a previously reported study on Dendrobium officinale stem, in which the researchers found the FD method to be superior in terms of maximum color retention potential as compared to sun drying, $\mathrm{HAD}$, vacuum drying, infrared radiation drying, and FD methods (Meng et al., 2018). Another study by An et al. (2016) reported that a bitter gourd sliced sample obtained using the FD method showed better color retention than the sample of HAD and infrared radiation drying method.

\section{Effect of drying treatments on $a_{w}$ and rehydration capacity of $B$. monnieri}

The $a_{w}$ value indicates the available water for the spread of microorganisms that cause spoiling and degradation of the physicochemical quality of dehydrated foodstuffs. The $a_{w}$ value is a key parameter commonly used to test the stability and shelf life of dehydrated foodstuffs at the time of storage (Mathlouthi et al., 2001). The results of $a_{w}$ studies of the dried samples obtained from the six drying methods are presented in Table 1. As shown in the table, the dried sample of the FD method showed a significant difference $(P \leq 0.05)$ with the lowest $\mathrm{a}_{\mathrm{w}}$ value $\left(\mathrm{a}_{\mathrm{w}}=0.15\right)$ as compared to the samples of the other drying methods, i.e., $\mathrm{HAD}$ at $70^{\circ} \mathrm{C}$ $\left(0.37 \pm 0.00^{\mathrm{c}}\right)<\mathrm{MD}$ at $300 \mathrm{~W}\left(0.38 \pm 0.01^{\mathrm{c}}\right)<\mathrm{MD}$ at $600 \mathrm{~W}\left(0.40 \pm 0.01^{\mathrm{b}}\right)<\mathrm{SD}\left(0.41 \pm 0.00^{\mathrm{b}}\right)<\mathrm{HAD}$ at $50^{\circ} \mathrm{C}$ $\left(0.43 \pm 0.01^{\mathrm{a}}\right)$. This indicates that the FD method could be an ideal drying method to extend the product shelf life. The rehydration results of the dried $B$. monnieri samples expressed as percentage are shown in Table 1. We observed that the rehydration ratio of the dried $B$. monnieri samples was increased with the decrease in temperature and microwave power (FD: $5.20 \pm 0.46^{\text {a }}$; MD: $4.52 \pm 0.51^{\mathrm{ab}}$ at $300 \mathrm{~W}, 3.97 \pm 0.23^{\mathrm{bc}}$ at $600 \mathrm{~W}$; HAD: $3.85 \pm 0.29^{\text {bc }}$ at $50^{\circ} \mathrm{C}, 2.92 \pm 0.14^{\mathrm{d}}$ at $70^{\circ} \mathrm{C}$; SD: $\left.3.14 \pm 0.18^{\text {cd }}\right)$. On the basis of the $\mathrm{a}_{\mathrm{w}}$ results, it was determined that the FD method is an ideal drying one among the six drying methods. Moreover, similar findings were reported in the study of the effect of two drying methods (HAD and FD) on Thai green curry leaves (Chaloeichitratham et al., 2018). Most of the oxidative and enzymatic reactions and the growth of microorganisms (bacteria, mold, and yeast) can be stopped in dried foodstuff with an $\mathrm{a}_{\mathrm{w}}$ value of $\leq 0.6$ (Perera et al., 2005). However, there is a possibility of a non-enzymatic browning reaction for the $\mathrm{a}_{\mathrm{w}}$ value within the range of 0.4 to 0.6 . Hence, reducing the $\mathrm{a}_{\mathrm{w}}$ value of food to $\leq 0.4$ is important to inhibit the browning reaction and increase the shelf life of the dried products (Wang et al., 2014). The quality of a dried food is determined in terms of the rate and extent of rehydration depending on cellular structure disruption and chemical changes occurring during the dehydration process. This finding indicates that the FD method is more suitable among the six drying methods. This result is similar to a previously reported finding related to interesting color retention potential of a freeze-dried strawberry product 


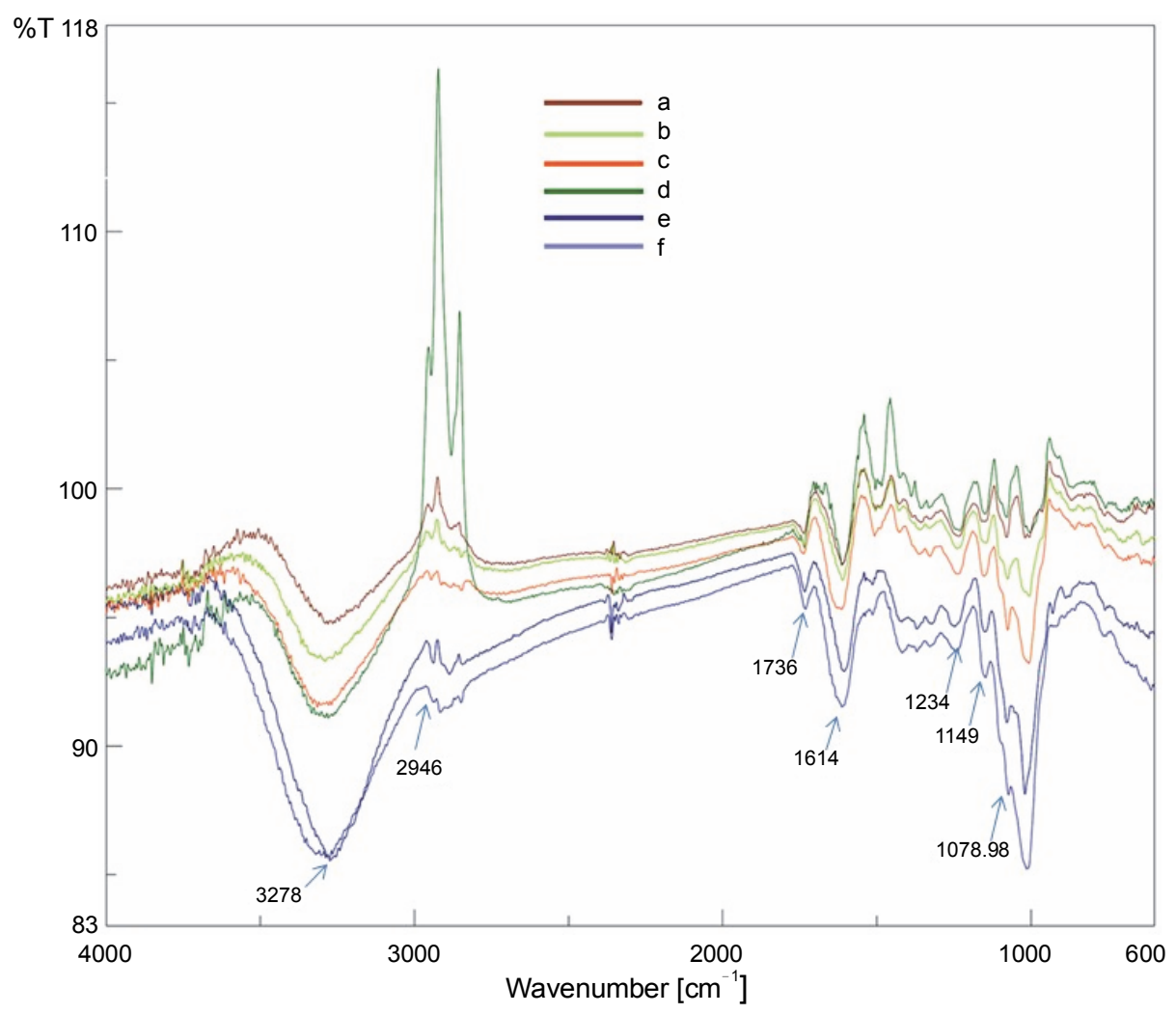

Fig. 2. Fourier transform infrared (FT-IR) spectra of $B$. monnieri samples dehydrated by microwave drying at $300 \mathrm{~W}(\mathrm{a})$, microwave drying at $600 \mathrm{~W}(\mathrm{~b})$, hot air drying at $70^{\circ} \mathrm{C}(\mathrm{c})$, hot air drying at $50^{\circ} \mathrm{C}(\mathrm{d})$, solar drying (e), and freeze drying (f)

in comparison to convective dried and vacuum microwave dried product (Wojdyło et al., 2009). Another study illustrated that freeze-dried cranberries showed a maximum rehydration ratio, which was better than that achieved in cranberries treated with hot air drying, ovendrying, and MD (Beaudry et al., 2004). Generally, samples dried under optimal conditions rehydrate quickly and completely as compared to poorly dried samples. The decreasing rehydration ratio with the increase in temperature and microwave power may be due to irreversible cellular damage and the shrinkage of cellular structure, which leads to decreased porosity (Feng et al., 2021). Lower porosity and higher bulk density reduce the rehydration capacity of the dried sample. Thus, the significant variation $(P<0.05)$ in the rehydration capacity of the dried $B$. monnieri samples may be due to the different degrees of structural damage in the cellular structure of the capillary, thereby causing changes in the osmotic behavior of the cell and resulting in lower transmission of water through the surface during rehydration.

\section{Effect of drying treatments on the in vitro antioxidant activity of $B$. monnieri}

In this study, the in vitro antioxidant activity of the six dried B. monnieripowdered samples was determined by the DPPH assay, and the obtained results are shown in Table 2. DPPH is a stable free radical that is extensively used to test the free radical scavenging activity of antioxidants (Yan et al., 2019). In the DPPH assay, the strongest DPPH scavenging ability was found in samples dried using the MD $300 \mathrm{~W}$ method $\left(1.12 \pm 0.01^{\mathrm{e}}\right)$, followed by $\mathrm{MD}$ at $600 \mathrm{~W}\left(1.55 \pm 0.09^{\mathrm{d}}\right), \mathrm{HAD}$ at $50^{\circ} \mathrm{C}$ $\left(1.90 \pm 0.10^{\mathrm{c}}\right), \mathrm{FD}\left(2.25 \pm 0.10^{\mathrm{b}}\right), \mathrm{SD}\left(2.34 \pm 0.01^{\mathrm{b}}\right)$, and $\mathrm{HAD}$ at $70^{\circ} \mathrm{C}\left(3.55 \pm 0.09^{\mathrm{a}}\right)$. The findings of this study corroborate with many previously reported results showing that the decrease in antioxidant activity might be due to intensive oxidation caused by long drying processes and high temperatures (i.e., $60^{\circ} \mathrm{C}$ and $70^{\circ} \mathrm{C}$ ) (Nindo et al., 2003; Wojdyło et al., 2009; Dwivedy et al., 2012; Periche et al., 2015). Moreover, we assumed that the increased antioxidant activity of MD and SD dried 
Table 2. Effect of microwave drying (MD), hot air drying (HAD), freeze drying (FD), solar drying (SD) method on the antioxidant capacity of $B$. monnieri samples

\begin{tabular}{l|c}
\hline \multicolumn{1}{c|}{ Drying methods } & DPPH IC $_{50}[\mathrm{mg} / \mathrm{ml}]$ \\
\hline $\mathrm{MD}[300 \mathrm{~W}]$ & $1.12 \pm 0.01^{\mathrm{e}}$ \\
\hline $\mathrm{MD}[600 \mathrm{~W}]$ & $1.55 \pm 0.09^{\mathrm{d}}$ \\
\hline $\mathrm{HAD}\left[50^{\circ} \mathrm{C}\right]$ & $1.90 \pm 0.10^{\mathrm{c}}$ \\
\hline $\mathrm{HAD}\left[70^{\circ} \mathrm{C}\right]$ & $3.55 \pm 0.09^{\mathrm{a}}$ \\
\hline $\mathrm{SD}$ & $2.34 \pm 0.01^{\mathrm{b}}$ \\
\hline $\mathrm{FD}$ & $2.25 \pm 0.10^{\mathrm{b}}$ \\
\hline
\end{tabular}

The data in the table are presented as mean values $\pm \operatorname{SD}(n=3)$; values in the columnswith different superscripts express significant difference $(P<0.05)$, based on Tukey test; MD - microwave drying, HAD - hot air drying, FD - freeze drying, SD - solar drying

samples may be due to Maillard reaction, which is a nonenzymatic browning reaction that occurs at high temperature (Wojdyło et al., 2009). Hence, on the basis of the obtained results, it is recommended to use the MD method for the superior antioxidant property of the dried B. monnieri aerial sample.

\section{Effect of drying treatments on the bioactive components bacoside $A$ and bacopaside I of $B$. monnieri}

Bacoside A and bacopaside I are pharmaceutically important bioactive components of $B$. monnieri. In this study, HPLC analysis was performed to estimate the content of these bioactive components in fresh $B$. monnieri samples and the dried samples obtained with the six drying treatments, and the results are summarized in Table 3 and Figure 3. The highest bacoside A content was detected in the FD sample $\left(3.38 \% \pm 0.006^{\mathrm{b}}\right)$, followed by SD $\left(2.940 \% \pm 0.035^{\mathrm{b}}\right)$, HAD at $50^{\circ} \mathrm{C}(2.887 \% \pm$ $\left.\pm 0.011^{\mathrm{c}}\right), \mathrm{HAD}$ at $70^{\circ} \mathrm{C}\left(2.614 \% \pm 0.006^{\mathrm{d}}\right), \mathrm{MD}$ at $300 \mathrm{~W}$ $\left(2.304 \% \pm 0.007^{\mathrm{e}}\right)$, and $\mathrm{MD}$ at $600 \mathrm{~W}\left(2.287 \% \pm 0.007^{\mathrm{e}}\right)$. The bacopaside I content in the samples showed the following trend: FD $\left(0.620 \pm 0.002^{\mathrm{a}}\right)>\mathrm{HAD}$ at $50^{\circ} \mathrm{C}$ $\left(0.566 \pm 0.008^{\mathrm{b}}\right)>\mathrm{SD}\left(0.462 \pm 0.002^{\mathrm{c}}\right)>\mathrm{HAD}$ at $70^{\circ} \mathrm{C}$ $\left(0.431 \pm 0.001^{\mathrm{d}}\right)>\mathrm{MD}$ at $600 \mathrm{~W}\left(0.335 \pm 0.003^{\mathrm{e}}\right)>\mathrm{MD}$ at $300 \mathrm{~W}\left(0.226 \pm 0.001^{\mathrm{f}}\right)$. The decrease in the content of bacoside A and bacopaside I in samples obtained with the six drying methods, from FD to MD, may be due to an increase in temperature and microwave power, which leads to an increase in the compactness of cellular structure and decrease in porosity and consequently hinders the extraction of bioactive compounds from the
Table 3. Effect of different drying methods in bioactive constituents (bacoside A and bacopaside I) content of $B$. monnieri sample

\begin{tabular}{l|c|c}
\hline \multirow{2}{*}{ Drying methods } & \multicolumn{2}{c}{ Content [\%] } \\
\cline { 2 - 3 } & bacoside A & bacopaside I \\
\hline Fresh & $0.228 \pm 0.001^{\mathrm{a}}$ & $0.043 \pm 0.001^{\mathrm{g}}$ \\
\hline $\mathrm{MD}[300 \mathrm{~W}]$ & $2.304 \pm 0.007^{\mathrm{e}}$ & $0.226 \pm 0.001^{\mathrm{f}}$ \\
\hline $\mathrm{MD}[600 \mathrm{~W}]$ & $2.287 \pm 0.007^{\mathrm{e}}$ & $0.335 \pm 0.003^{\mathrm{e}}$ \\
\hline $\mathrm{HAD}\left[50^{\circ} \mathrm{C}\right]$ & $2.887 \pm 0.011^{\mathrm{c}}$ & $0.566 \pm 0.008^{\mathrm{b}}$ \\
\hline $\mathrm{HAD}\left[70^{\circ} \mathrm{C}\right]$ & $2.614 \pm 0.006^{\mathrm{d}}$ & $0.431 \pm 0.001^{\mathrm{d}}$ \\
\hline $\mathrm{SD}$ & $2.940 \pm 0.035^{\mathrm{b}}$ & $0.462 \pm 0.002^{\mathrm{c}}$ \\
\hline $\mathrm{FD}$ & $3.389 \pm 0.006^{\mathrm{b}}$ & $0.620 \pm 0.002^{\mathrm{a}}$ \\
\hline
\end{tabular}

The data in the table are mean values $\pm \mathrm{SD}(n=3)$; values in the columns with different superscripts express significant difference $(P<0.05)$, based on Tukey test; MD - microwave drying, HAD - hot air drying, FD - freeze drying, SD - solar drying

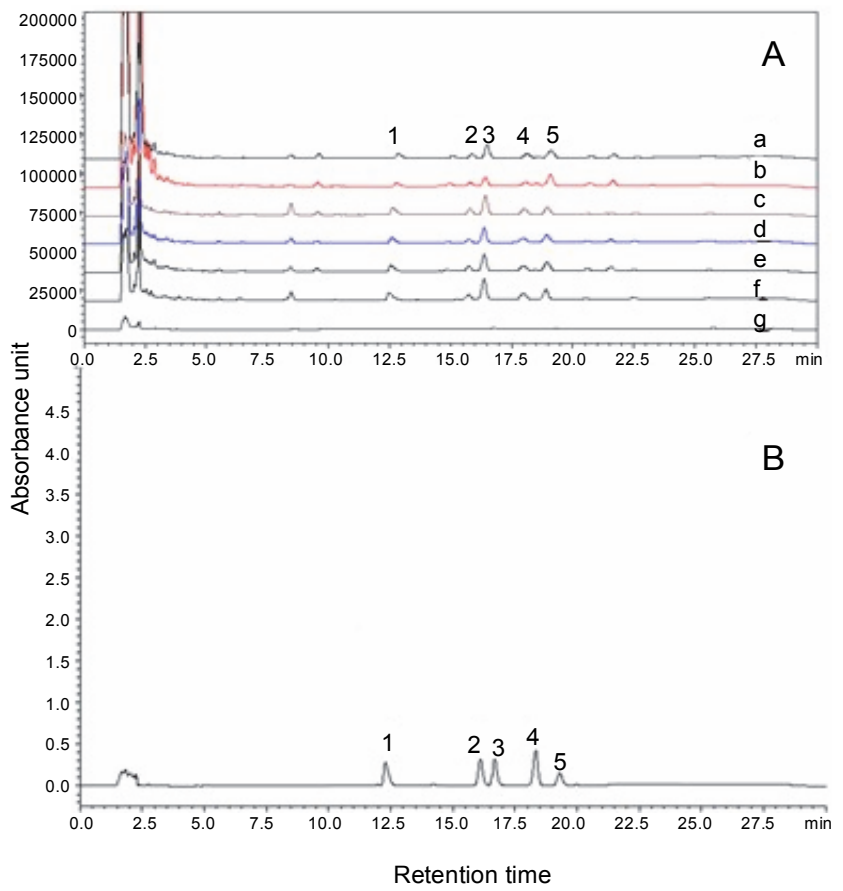

Fig. 3. HPLC comparative chromatogram of reference standards (B): bacopaside I (1) and bacoside A (bacoside A3 (2), bacopaside II (3), jujubogenin isomer of bacopasaponin C (4), and bacopasaponin C (5)) with the six dried B. monnieri samples (A): microwave drying at $300 \mathrm{~W}$ (a), microwave drying at $600 \mathrm{~W}$ (b), hot air drying at $50^{\circ} \mathrm{C}$ (c), hot air drying at $70^{\circ} \mathrm{C}$ (d), solar drying (e), freeze-drying (f), and fresh sample (g)

dried samples. The bacoside A content in the dried sample of the FD method was $3.389 \%$, which was significantly higher than the previously reported bacoside A content of $2.02 \%$ in the B. monnieri aerial part sample 
dried using a cabinet drier (Silpa et al., 2019). FD is a low temperature drying process in which free water molecules are converted into ice, and this ice form prevents the degradation of active constituents, including bacoside A and bacopaside I content, in B. monnieri. Nianmuy et al. (2013) reported that in the drying of Centela asiatica, hydrolysis of glycoside to aglycones occurred in the initial phase of temperature increase; however, a further increase in temperature led to the degradation of the glycoside. Moreover, in the processing of pomegranate peel, the FD method was found to be the best method in terms of maximum retention of natural bioactive compounds, which was better than that achieved using the oven drying method (Mphahlele et al., 2016). From the results, it could be concluded that the FD method of drying is best suitable to obtain the maximum yield of bacoside $\mathrm{A}$ and bacopaside I content.

\section{Effect of drying treatments on the functional characteristics of $B$. monnieri}

FT-IR is a reliable, sensitive, and high-resolution analytical technique for elucidating the structural and functional information of chemical constituents. FT-IR analysis provides a rapid and non-destructive investigation of biomolecular composition and enables to develop a fingerprint of plant extracts or powders. In the present study, the FT-IR analysis revealed various structural and functional information of the chemical constituents of $B$. monnieri powdered sample. FT-IR spectrum profiles of the six $B$. monnieri samples obtained by the different drying treatments are shown in Figure 2. No remarkable differences were detected among the FT-IR spectra of the $B$. monnieri samples obtained from the different drying treatments, indicating that there were no conformational changes in the functional groups of the chemical constituents. In the FT-IR spectrum profiles (Fig. 2) of the six $B$. monnieri aerial samples dried using different treatments, a strong broad band at $3278.79 \mathrm{~cm}^{-1}$ was attributed to the $\mathrm{O}-\mathrm{H}$ stretching of the carboxylic groups. This finding is in agreement with the previously reported data regarding the $\mathrm{O}-\mathrm{H}$ stretching vibration of bitter gourd polysaccharides (Yanet al., 2019). The peak at $2945.73 \mathrm{~cm}^{-1}$ was attributed to the $\mathrm{C}-\mathrm{H}$ stretching vibration of $\mathrm{CH}, \mathrm{CH} 2$, and $\mathrm{CH} 3$ (Wojdyło et al., 2009; Feng et al., 2021). The peak at $1735.62 \mathrm{~cm}^{-1}$ was ascribed to the strong $\mathrm{C}=\mathrm{O}$ stretching vibration of aldehyde
(Kareru et al., 2008). The absorption peak at $1614.13 \mathrm{~cm}^{-1}$ was ascribed to the strong $\mathrm{C}=\mathrm{C}$ stretching vibration of the $\alpha, \beta$-unsaturated ketone functional group (Jeyasri et al., 2020). The peak value of $1505.17 \mathrm{~cm}^{-1}$ was attributed to the strong $\mathrm{N}-\mathrm{O}$ stretching vibration of the nitro compound. The peak at $1231.33 \mathrm{~cm}^{-1}$ was assigned to the medium $\mathrm{C}-\mathrm{N}$ stretching vibration of amine. The peak at $1149.37 \mathrm{~cm}^{-1}$ was attributed to the strong $\mathrm{C}-\mathrm{O}$ stretching vibration of aliphatic ether. The peak at $1078.98 \mathrm{~cm}^{-1}$ was attributed to the strong $\mathrm{S}=\mathrm{O}$ stretching vibration of sulfoxide.

\section{Conclusions}

The results of the present study suggest that drying plays an important role in value addition of $B$. monnieri samples. According to the required drying duration, MD was the best method, followed by HAD, SD, and FD. Although the FD method took the longest time for drying, it resulted in better color retention, lower $\mathrm{a}_{\mathrm{w}}$, and higher content of bioactive components (bacoside $\mathrm{A}$ and bacopaside I) as compared to the other drying methods such as SD, HAD, and MD. The contents of bacoside A and bacopaside I that define the quality and market value of the commercial product of $B$. monnieri were considerably higher in the freeze-dried sample than in the other five samples. Moreover, FD is considered to be the best method as lesser $a_{w}$ was observed in the freezedried sample, which results in a more thermo stable product with a higher shelf life. This study clearly showed that the FD method can be used for the drying of B. monnieri samples with minimum loss of bacoside A and bacopaside I content.

\section{References}

An K., Zhao D., Wang Z., Wu J., Xu Y., Xiao, G. (2016) Comparison of different drying methods on Chinese ginger (Zingiber officinale Roscoe): changes in volatiles, chemical profile, antioxidant properties, and microstructure. Food Chem. 197: 1292-1300.

Atungulu G.G., Sadaka S. (2019) Postharvest technology: rice drying. In Rice. AACC International Press: 473-515.

Beaudry C., Raghavan G.S.V., Ratti C., Rennie T.J. (2004) Effect of four drying methods on the quality of osmotically dehydrated cranberries. Dry. Technol. 22: 521-539.

Bhandari P., Sendri N., Devidas S.B. (2020) Dammarane triterpenoid glycosides in Bacopa monnieri: a review on chemical diversity and bioactivity. Phytochemistry 172: 112276 . 
Bhatia G., Dhuna V., Dhuna K., Kaur M., Singh J. (2017) Bacopa monnieri extracts prevent hydrogen peroxide-induced oxidative damage in a cellular model of neuroblastoma IMR32 cells. Chin. J. Nat. Med. 15:834-846.

Chaloeichitratham N., Mawilai P., Pongsuttiyakorn T., Pornchalermpong P. (2018) Effect of drying methods on properties of green curry powder. [in:] MATEC Web of Conferences 192: 03023.

Christopher C., Johnson A.J., Mathew P.J., Baby S. (2017) Elite genotypes of Bacopa monnieri, with high contents of Bacoside $A$ and Bacopaside I, from southern Western Ghats in India. Ind. Crops. Prod. 98: 76-81.

Dwivedy S., Rayaguru K., Sahoo G.R. (2012) Effect of drying methods on quality characteristics of medicinal Indian borage (Coleus aromaticus) leaves. J. Food Process. Technol. 3: 1-6.

Feng Y., Xu B., Yagoub A.E.A., Ma H., Sun Y., Xu X., Yu X., Zhou C. (2021) Role of drying techniques on physical, rehydration, flavor, bioactive compounds and antioxidant characteristics of garlic. Food Chem. 343: 128404.

Hu S., Zhao G., Zheng Y., Qu M., Jin Q., Tong C., Li W. (2017) Effect of drying procedures on the physicochemical properties and antioxidant activities of polysaccharides from Crassostrea gigas. PLoS One 12: 0188536.

Izli N., Isik E. (2014) Effect of different drying methods on drying characteristics, colour and microstructure properties of mushroom. J. Food. Nutr. Res. 53: 105-116.

Jeyasri R., Muthuramalingam P., Suba V., Ramesh M., Chen J.T. (2020) Bacopa monnieri and their bioactive compounds inferred multi-target treatment strategy for neurological diseases: a cheminformatics and system pharmacology approach. Biomolecules 10: 536.

Kareru P.G., Keriko J.M., Gachanja A.N., Kenji G.M. (2008) Direct detection of triterpenoid saponins in medicinal plants. Afr. J. Tradit. Complement Altern. Med. 5: 56-60.

Kozarski M., Klaus A., Niksic M., Jakovljevic D., Helsper J.P., Van Griensven L.J. (2011) Antioxidative and immunomodulating activities of polysaccharide extracts of the medicinal mushrooms Agaricusbisporus, Agaricus brasiliensis, Ganoderma lucidum and Phellinus linteus. Food Chem. 129: 1667-1675.

Li H., Xie L., Ma Y., Zhang M., Zhao Y., Zhao X. (2019) Effects of drying methods on drying characteristics, physicochemical properties and antioxidant capacity of okra. Lebensmittel-Wissenschaft Technol. 101: 630-638.

Mathlouthi M. (2001) Water content, water activity, water structure and the stability of foodstuffs. Food Control 12: 409-417.

Meng Q., Fan H., Li Y., Zhang L. (2018) Effect of drying methods on physico-chemical properties and antioxidant activity of Dendrobium officinale. Food. Meas. 12: 1-10.

Mphahlele R.R., Fawole O.A., Makunga N.P., Opara U.L. (2016) Effect of drying on the bioactive compounds, antioxidant, antibacterial and antityrosinase activities of pomegranate peel. BMC Complement Altern. Med. 16: 1-12.
Nagaya K., Li Y., Jin Z., Fukumuro M., Ando Y., Akaishi A., (2006) Low-temperature desiccant-based food drying system with airflow and temperature control. J. Food Eng. 75: 71-77.

NguyenV.T., Van Vuong Q., Bowyer M.C., Van Altena I.A., Scarlett C.J. (2015) Effects of different drying methods on bioactive compound yield and antioxidant capacity of Phyllanthus amarus. Dry. Technol. 33: 1006-1017.

Nianmuy C., Charoenchaitrakool M., Mayachiew P., Devahastin S. (2013) Bioactive compounds and bioactivities of Centella asiatica (L.) Urban prepared by different drying methods and conditions. Dry. Technol. 31: 2007-2015.

Nindo C., Sun T., Wang S.W., Tang J., Powers J.R. (2003) Evaluation of drying technologies for retention of physical quality and antioxidants in asparagus (Asparagus officinalis, L.). Lebensmittel-Wissenschaft Food Sci. Technol. 36: 507-516.

Palethorpe H.M., Tomita Y., Smith E., Pei J.V., Townsend A.R., Price T.J., Young J.P., Yool A.J., Hardingham J.E. (2018) The aquaporin 1 inhibitor bacopaside II reduces endothelial cell migration and tubulogenesis and induces apoptosis. Int. J. Mol. Sci. 19: 653.

Perera C.O. (2005) Selected quality attributes of dried foods. Dry. Technol. 23: 717-730.

Periche A., Castelló M.L., Heredia A., Escriche I. (2015) Influence of drying method on steviol glycosides and antioxidants in Stevia rebaudiana leaves. Food Chem. 172: $1-6$.

Rahimmalek M., Goli S.A. (2013) Evaluation of six drying treatments with respect to essential oil yield, composition and color characteristics of Thymys daenensis subsp. daenensis. Celak leaves. Ind. Crops. Prod. 42: 613-619.

Ray A., Jena S., Kar B., Patnaik J., Panda P.C., Nayak S. (2019) Chemical composition and antioxidant activities of essential oil of Hedychium greenii and Hedychium gracile from India. Nat. Prod. Res. 33: 1482-1485.

Rudra S.G., Singh H., Basu S., Shivhare U.S. (2008) Enthalpy entropy compensation during thermal degradation of chlorophyll in mint and coriander puree. J. Food. Eng. 86: 379-387.

Saha P.S., Sarkar S., Jeyasri R., Muthuramalingam P., Ramesh M., Jha S. (2020) In Vitro propagation, phytochemical and neuropharmacological profiles of Bacopa monnieri (L.) Wettst.: a review. Plants 9: 411.

Saini N., Singh D., Sandhir R. (2019) Bacopa monnieri prevents colchicine-induced dementia by anti-inflammatory action. Metab. Brain Dis. 34: 505-518.

Shivanna V.B., Subban N. (2014) Effect of various drying methods on flavor characteristics and physicochemical properties of dried curry leaves (Murraya koenigii L. Spreng). Dry. Technol. 32: 882-890.

Silpa S.G., Smitha G.R., Ranjitha K. (2021) Drying and packaging methods impact the bacoside profile and microbiological quality of Brahmi herb (Bacopa monnieri L.) during storage. Ind. Crops Prod. 159: 113064. 
Silpa S.G., Smitha G.R., Sadananda G.K., Ranjitha K., Gowda A.P., Umesha K. (2019) Effect of drying and packaging methods on physico-chemical and phytochemical composition of Brahmi (Bacopa monnieri L.) with respect to shelf life enhancement. Med. Plants Int. J. Phytomed. Rel. Ind. 11: 73-86.

Therdthai N., Zhou W. (2009) Characterization of microwave vacuum drying and hot air drying of mint leaves (Mentha cordifolia Opiz ex Fresen). J. Food. Eng. 91: 482-489.

Vega-Gálvez A., Ah-Hen K., Chacana M., Vergara J., MartínezMonzó J., García-Segovia P., Lemus-Mondaca R., Di Scala K. (2012) Effect of temperature and air velocity on drying kinetics, antioxidant capacity, total phenolic content, colour, texture and microstructure of apple (var. Granny Smith) slices. Food Chem. 132: 51-59.

Verma M. (2014) Ethno-medicinal and antimicrobial screening of Bacopa monnieri (1.) Pennell. J. Phytol. 6: 1-6.

Wang H., Zhang M., Mujumdar A.S. (2014) Comparison of three new drying methods for drying characteristics and quality of shiitake mushroom (Lentinus edodes). Dry. Technol. 32: 1791-1802.
Williams R., Münch G., Gyengesi E., Bennett L. (2014) Bacopa monnieri (L.) exerts anti-inflammatory effects on cells of the innate immune system in vitro. Food Funct. 5: 517-520.

Wojdyło A., Figiel A., Oszmianski J. (2009) Effect of drying methods with the application of vacuum microwaves on the bioactive compounds, color, and antioxidant activity of strawberry fruits. J. Agric. Food Chem. 57: 1337-1343.

Yan J.K., Wu L.X., Qiao Z.R., Cai W.D., Ma H. (2019) Effect of different drying methods on the product quality and bioactive polysaccharides of bitter gourd (Momordica charantia L.) slices. Food Chem. 271: 588-596.

Yuan Q., He Y., Xiang P.Y., HuangY.J., Cao Z.W., Shen S.W., Zhao L., Zhang Q., Qin W., Wu D.T. (2020) Influences of different drying methods on the structural characteristics and multiple bioactivities of polysaccharides from okra (Abelmoschus esculentus). Int. J. Biol. Macromol. 147: 1053-1063. 